\title{
IDENTIFIKASI KARAKTER BANGUNAN ISLAMI PADA PESMA PUTRI KH MAS MANSUR UMS
}

\author{
Ikrima Iffah Shochfah, Widyastuti Nurjayanti \\ Program Studi Teknik Arsitektur, Fakultas Teknik, Universitas Muhammadiyah Surakarta \\ Jl. A. Yani Tromol Pos 1 Pabelan Kartasura Sukoharjo 57102 Telp 0271-717417 \\ E-mail: springsunnybunny@gmail.com, nurjy22@gmail.com
}

\begin{abstract}
ABSTRAK
Pesantren Mahasiswa (Pesma) Putri K.H. Mas Mansur UMS, adalah sebuah asrama mahasiswa yang difungsikan sebagai pesantren mahasiswa.sebagai tempat tinggal bagi mahasiswa internasional dan mahasiswa lokal. Pesantren Mahasiswa ini, didukung oleh program Islami dan sebaiknya diikuti oleh desain ruangan yang Islami pula. Urgensi riset ini untuk mengetahui apakah Pesma Putri K.H. Mas Mansur UMS sudah menerapkan kaidah aturan Islami dalam bangunannya. Tujuan penelitian ini adalah: (a). mengidentifikasi dan menemukan karakter bangunan Islami yang sudah diterapkan pada Pesma K.H. Mas Mansur UMS. b). Menganalisis perwujudan karakter bangunan Islami pada elemen arsitektur bangunan Pesma KH Mas Mansur UMS. Metode penelitian yang digunakan secara umum adalah metode kualitatif. Analisis menggunakan metode deskriptif komparatif, menggambarkan kondisi faktual dengan mengemukakan fakta-fakta yang ada di lapangan serta membandingkannya antara satu kondisi dengan kondisi lainnya. Hasil Penelitian menunjukkan bahwa KH Mas Mansur mempunyai sebagian besar karakter bangunan Islami, mulai dari zonasi, tata ruang, ornamen seni hias Islami, lay out interior peruangan, orientasi bangunan dan fasad bangunan.
\end{abstract}

Kata Kunci: karakter, bangunan, islami, pesma putri

\section{PENDAHULUAN}

Semakin berkembangnya UMS yang diikuti oleh peningkatan jumlah mahasiswa dari tahun ketahun dan keragaman daerah asal mahasiswa memerlukan pemenuhan kebutuhan tempat tinggal sebagai faktor penunjang kegiatan istirahat dan belajar. UMS sekarang telah berkembang dan memiliki mahasiswa sekitar 23.357, terdiri dari mahasiswa Diploma dan Strata 1, serta 4.211 mahasiswa pascasarjana membutuhkan asrama yang berkualitas. Mereka memerlukan tempat tinggal yang layak, sebagian besar indekost di rumah warga sekitar kampus, dan sebagian kecil ditampung di Pesantren Mahasiswa Internasional $\mathrm{KH}$ Mas Mansur UMS. Universitas Muhammadiyah Surakarta merupakan salah satu amal usaha Muhammadiyah di bidang pendidikan, bersemboyan "Wacana Keilmuan dan Keislaman", yakni mewujudkan kampus berbudaya Islami yang menguasai ilmu pengetahuan dan keterampilan yang dilandasi nilai-nilai keislaman. (http://pmb.ums.ac.id2012/Fakta UMS).

Pesantren Mahasiswa Internasional $\mathrm{KH}$ Mas Mansur telah menerapkan program Islami untuk membina generasi muda, khususnya mahasiswa sebagai kader pejuang dalam menghadapi dinamika dunia Islam baik secara lokal maupun global, dengan berupaya untuk mewujudkan pesantren mahasiswa menjadi center of excellence. Setiap mahasantri diberikan pembinaan secara intensif meliputi Tauhid/Aqidah, Ibadah, Muamalah dan Akhlaq, diharapkan akan mampu memiliki kepandaian/kecakapan dalam berbahasa Inggris dan bahasa Arab. Syarat lulus dari pesantren adalah setiap mahasantri wajib mengikuti evaluasi pembinaan yang diadakan setiap semester dan akan mendapatkan sertifikat kelulusan sesuai dengan disiplin ilmu yang ditekuni 
selama di pesantren. Bekal ilmu yang didapat selama di pesantren diharapkan berguna bagi mahasantri untuk memiliki kesiapan baik secara fisik dan mental untuk berdakwah dan berjuang menyebarkan kemuliaan ajaran Islam di tempat tinggalnya masing-masing.

UMS mempunyai 2 gedung asrama, yaitu asrama putra dan asrama putri. Pada penelitian ini dipilih sebagai objek penelitian adalah pesantren mahasiswa putri. apakah bangunan, tata ruang dan elemen arsitektur telah menerapkan aturan Islam dan apakah karakter bangunan Islami sudah terekspresikan pada elemen bangunannya.

Tujuan penelitian ini adalah: (a). mengidentifikasi dan menemukan karakter bangunan Islami pada Pesma Putri K.H. Mas Mansur UMS; (b). menganalisis perwujudan karakter bangunan Islami pada elemen arsitektur bangunan Pesma Putri K.H. Mas Mansur UMS. Manfaat Penelitian adalah sebagai dokumen akademik yang dapat digunakan sebagai referensi untuk perencanaan dan perancangan sebuah bangunan yang berkarakter Islam.

\section{STUDI PUSTAKA}

\section{Tinjauan tentang Pesantren}

Menurut Prasodjo Sudjoko (1975), elemen-elemen dalam Pondok Pesantren (Ponpes) ditinjau dari segi fisik terdapat adanya masjid, madrasah, pondok/asrama, perumahan ustadz/tamu dan fasilitas penunjang. Ditinjau dari pelaku yang ada dalam sebuah pondok terdiri dari santri, Kyai, Ustadz, Pengelola dan Instruktur. Jenis Pondok Pesantren dapat dibedakan berdasarkan kompleksitasnya, macam fasilitas yang ada, dan program yang digunakan. Peran dari pendidikan pondok pesantren sesuai dengan program pendidikan, yaitu membantu perkembangan jiwa siswa/santri, maupun membantu mengarahkan tingkah laku mereka. Fungsi Ponpes adalah mendidik para calon ulama yang akan menjadi penerus/penyebar ilmu keagamaan Islam pada masyarakat. Sistem Pendidikan di Ponpes sebagai berikut: (a) jenjang pendidikannya dimulai dari setaraf pendidikan tingkat dasar sampai dengan pendidikan tingkat atas. (b) ponpes menggunakan dua sistem pendidikan yaitu pendidikan formal (pendidikan umum) dan pendidikan non formal (pendidikan ke- agamaan). (c) para santri yang belajar menghayati keagamaan, bertempat tinggal di pondok selama mengikuti pendidikan dalam pesantren. Sistem Pengajaran Ponpes dibagi menjadi dua yaitu: (a) sistem klasikal yaitu pendidikan dilakukan seperti yang dilakukan pada pendidikan umum, yaitu menggunakan ruang-ruang kelas. (b). sistem non klasikal yaitu pendidikan dilakukan di Masjid atau rumah Kyai dengan cara sorogan, bandongan, wetonan, muzakaroh, dan mejelis ta'lim.

\section{Karakter Bangunan Islami}

Menurut Rasdi (2003), arsitektur Islam adalah arsitektur yang berlandaskan pada Al Qur'an dan Sunnah sebagai peninggalan utama dari Rasulullah. Amhar (2009), mendefinisikan arsitektur Islam sebagai suatu rancang bangun yang didasari oleh aqidah Islam dan memenuhi norma-norma dalam syariat Islam. Perwujudan budaya Islami yang dicita-citakan dapat dituangkan dalam bentuk fisik dan non fisik, yaitu dengan perwujudan lingkungan binaan/bangunan yang Islami dan perilaku penghuni yang Islami. Perwujudan fisik arsitektur yang Islami dapat diperoleh dengan perpaduan yang harmonis antara unsur filosofis dan unsur simbolis yang sesuai dengan kaidah Islam (Noe'man, 2003). Pesma disetarakan dengan rumah tinggal, dan hal tentang rumah tinggal telah disinggung dalam AI Qur'an dan Hadits. Diantaranya ditemukan tentang hakekat rumah tinggal adalah untuk mendapatkan perlindunganNya dibumi (surat An-Nahl ayat 80); rumah tempat tinggal mempunyai karakter privasi yang tinggi (surat An-Nur ayat 27).

Bangunan Islami adalah bangunan yang berfungsi untuk umat Islam, didalamnya terdapat berbagai fungsi yang mendukung ibadah dan muamalah. Karakter Bangunan Islami akan dapat dikenali dari berbagai fungsi dan karakternya dan dapat diidentifikasi melalui adanya:

a. Pengamalan Islam sebagai 'Way of Life', terekspresikan pada perilaku penghuni yang berfilosofi Kelslaman, meliputi Tauhid, Ibadah, Muamalah, Syariah dan Akhlaq (adab, tatacara), yang akan berpengaruh pada bentukan wadah arsitektur dan peruangannya (Nurjayanti, 2012) 
b. Pentingnya orientasi pada Ka,bah dan Kiblat yang berdampak pada fungsi ruang ibadah, sebagai ruang sholat dan penataan lay out interior ruang tidur dan ruang lainnya. Ada beberapa sunah Rasullulah yang dapat di aplikasikan pada kamar tidur, berhubungan dengan posisi tidur yang disunahkan Rasulullah yaitu tidur membujur kepala di utara dan kaki di Selatan, serta badan miring menghadap pada Kiblat (lokasi Indonesia).

c. Pentingnya Hijab sebagai salah satu aturan Islam bagi perempuan, yang akan berdampak pada penataan zoning rumah tinggal dan hubungan antar ruang. Hijab dalam sebuah ruang dapat diartikan pembatas atau penghalang pandangan, jadi konsep hijab dapat diaplikasikan pada ruang tamu. Begitupun sekat-sekat ruangannya, sebisa mungkin ditata sedemikian rupa sehingga tidak membuat siapapun yang bertandang, bisa leluasa melihat kehidupan privasi para penghuni rumah (aurat rumah).

d. Pentingnya interior yang mendukung penerapan konsep arsitektur Islam dalam bangunan. Misalnya, bangunan akan bernilai ibadah bila ornamen-ornamen yang menghiasi sudut-sudut ruangnya tidak melambangkan kemaksiatan atau kesombongan pemiliknya. atau melambangkan simbol-simbol yang dilarang Islam, baik berupa lukisan, patung, foto atau hiasan lainnya. Pesan mengingat akhirat itu bisa juga kita sampaikan lewat kaset tilawah Al Qur'an atau senandung nasyid-nasyid Islami. Begitupun sekat-sekat ruangannya, sebisa mungkin ditata sedemikian rupa sehingga tidak membuat siapapun yang bertandang, bisa leluasa melihat kehidupan privasi para penghuni rumah (aurat rumah).

e. Seni hias Islami: adalah seni hias yang tidak ada unsur syiriknya, seperti hiasan floris, geometris dan kaligrafis (Sumalyo, 2000). Seni hias Islami yang ada dalam bangunan, baik interior maupun eksterior bertujuan untuk mengingatkan dan mendekatkan diri pada Allah (Nurjayanti, 2011)

f. Nilai-nilai Ke-Islaman yang berfungsi untuk melindungi jiwa, harta, keturunan dan agama, terwujud secara abstrak dan konkrit. Secara abstrak tercermin pada akhlaq/perilaku penghuni. Secara konkrit dapat ditemukan pada fisik bangunan terungkap pada eksterior, yang terwujud pada perlindungan keamanan dan privacy anggota keluarga dengan jalan berhijab, dan interior yang terwujud pada sistem zoning, hierarki ruang, kiblat sebagai orientasi kegiatan yang berdampak pada lay out furniture, perwujudan hijab fisik dan hijab perilaku, hiasan interior/benda pengingat Allah dan kebersihan ruang. (Nurjayanti,2004)

$\begin{array}{ccc}\text { Pesma diharapkan mempunyai } & \text { manasana untuk senantiasa melakukan }\end{array}$ penghambaan diri kepada-Nya terpancar dari penghuninya, kalau dianalogikan dengan asrama yang mengelola para mahasantri maka idealnya bangunan asrama mampu memanfaatkan ruang-ruangnya sebagai fasilitas untuk menempa seluruh anggota asrama/pesma agar menjadi muslim /muslimah yang sadar Islam. Pesma melahirkan generasi sadar ibadah dan dakwah, tarbiyah dan sadar bermuammalah untuk mengantarkan kemenangan Islam. Setiap relung bangunan asrama diharapkan memiliki makna, baik dari segi bentuk maupun pola tata ruangnya. Saat ini, para arsitek muda Islam telah bermunculan, maka bukan tidak mungkin peradaban Islam yang dahulu kala telah berjaya di bumi Allah ini akan kembali terlahir lewat tangan para Muhandis muda.

\section{METODE PENELITIAN}

Metode penelitian yang digunakan adalah penelitian lapangan dengan kasus tunggal dan diselesaikan dengan analisa diskriptip kualitatif. Langkah-langkah penelitian adalah: (a) persiapan, dan observasi awal; (b) pengumpulan data: wawancara, melakukan survey secara langsung, mencari data primer dan sekunder; (c) analisis deskriptifeksploratif, mendapatkan temuan penelitian, melakukan pembahasan; (d) kesimpulan dan rekomendasi.hasil penelitian

\section{HASIL PENELITIAN DAN PEMBAHASAN}

Secara administratif objek penelitian masuk dalam wilayah Kabupaten Sukoharjo, Kecamatan Kartasuro, berlokasi di Kampus IV UMS, dekat komplek UMS di Jalan Ahmad Yani Kartosuro, Surakarta. Jarak asrama putri ke lokasi kampus UMS sekitar 10 menit 
dengan berjalan kaki.Gambar 1 berikut ini menunjukkan lokasi obyek penelitian.

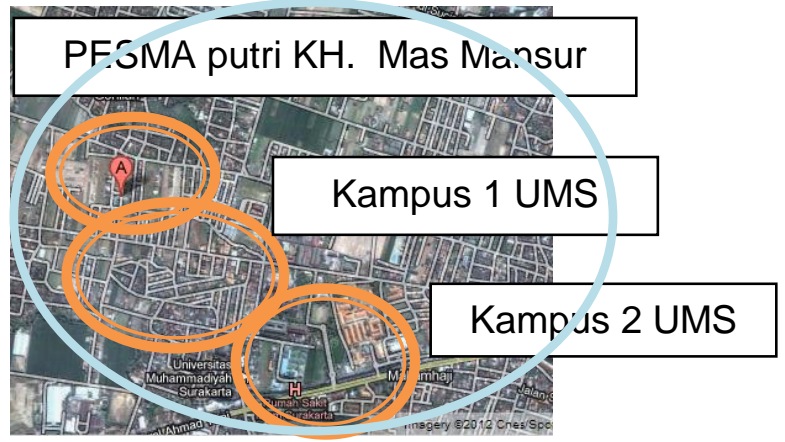

Gambar1. Lokasi Pesma Putri KH Mas MansurUMS (Sumber:www.googlemap.com, 2012)

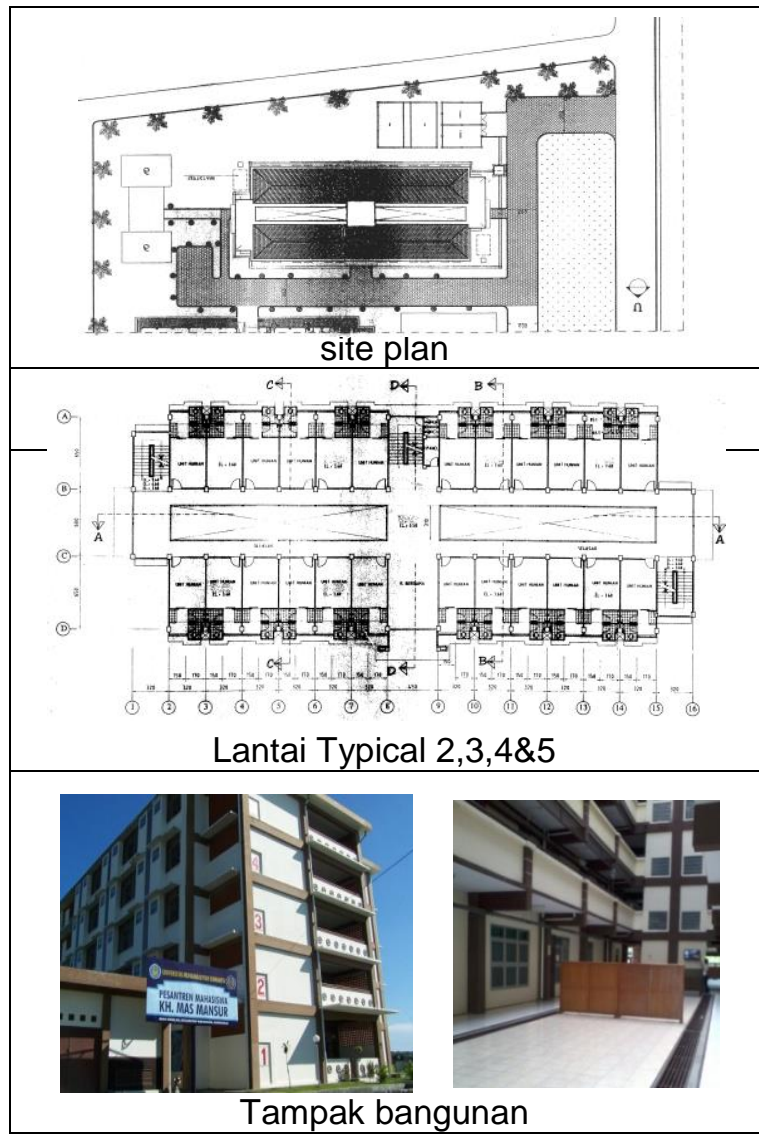

Gambar 2.Pesma Putri KH Mas Mansur UMS(Sumber: Survey UMS, 2012)

Data Fisik Pesma K.H. Mas Mansur UMS ditunjukkan pada Gambar2. Tabel 1 dibawah ini menunjukkan identifikasi karakter bangunan Islami.
Tabel 1.Analisi Diskriptip Karakter bangunan Islami pada Pesma Putri KH. Mas Mansur

\begin{tabular}{|c|c|}
\hline $\begin{array}{c}\text { Tolok } \\
\text { Kara } \\
\text { Islar }\end{array}$ & $\begin{array}{l}\text { Temuan Penelitian } \\
\text { (kondisi lapangan) }\end{array}$ \\
\hline $\begin{array}{l}\text { Adanya } \\
\text { Hijab } \\
\text { sebagai } \\
\text { pembatas, } \\
\text { pemisah } \\
\text { ruang } \\
\text { umum } \\
\text { dengan } \\
\text { privat. }\end{array}$ & $\begin{array}{l}\text { Pesma putri, sementara dihuni } \\
\text { mahasiswa dan mahasiswi, } \\
\text { sebab pesma putra baru } \\
\text { dibangun. Letak zona terpisah } \\
\text { antara asrama putra dan } \\
\text { putri.Sudah terdapat hijab } \\
\text { untuk mimisahkan area kantin } \\
\text { kegiatan pembelajaran putra } \\
\text { dan putri. Pada kantin ditemu- } \\
\text { kan hijab berupa pemisah dari } \\
\text { papan kayu untuk membe- } \\
\text { dakan wilayah putra dan putri, } \\
\text { tetapi seharusnya dipisah } \\
\text { dengan area asrama. Jadi } \\
\text { tidak dicampur dengan wilayah } \\
\text { asrama putri. Sebaiknya kelas } \\
\text { dipisah sesuai kegiatan } \\
\text { asrama putra atau putri begitu } \\
\text { juga ruang pengelola belum } \\
\text { dipisahkan dan masih menyatu } \\
\text { dengan asrama. }\end{array}$ \\
\hline $\begin{array}{c}\text { Adanya } \\
\text { Pemisahan } \\
\text { zona } \\
\text { umum dan } \\
\text { privat }\end{array}$ & $\begin{array}{l}\text { Pesma dibagi menjadi daerah } \\
\text { umum dan daerah privat. } \\
\text { Terdapat pemisahan area } \\
\text { pintu masuk asrama putra dan } \\
\text { putri.Pintu masuk utama pada } \\
\text { sisi sebelah Utara terlihat } \\
\text { jarang digunakan. Terdapat } \\
\text { ramp bagi mahasiswa yang } \\
\text { menggunakan kursi roda. } \\
\text { Pesma belum sepenuhnya } \\
\text { memenuhi syarat bangunan } \\
\text { Islami. Perletakan ruang kegia- } \\
\text { tan belajar dan pengelola } \\
\text { sebaiknya ada wilayah tersen- } \\
\text { diri. Belum ada nya wilayah } \\
\text { peribadatan yang mencukupi } \\
\text { jumlah mahasantri. (masjid } \\
\text { yang layak)ada tapi kapasitas } \\
\text { tidak mencukupi. }\end{array}$ \\
\hline $\begin{array}{l}\text { Adanya } \\
\text { Seni hias } \\
\text { Islami yg } \\
\text { tidak syirik }\end{array}$ & $\begin{array}{l}\text { Seni hias islami terdapat pada: } \\
\text { fasad bangunan, ornamen } \\
\text { plafond kantin, teralis jendela } \\
\text { dan teralis pintu. Belum ada } \\
\text { hiasan kaligrafi yg berfungsi } \\
\text { untuk mengingat Allah disetiap } \\
\text { kegiatan. }\end{array}$ \\
\hline & \\
\hline
\end{tabular}




\begin{tabular}{|c|l|}
\hline $\begin{array}{c}\text { Layout } \\
\text { interior yg } \\
\text { sesuai } \\
\text { sunnah }\end{array}$ & $\begin{array}{l}\text { WC atau toilet yang tidak } \\
\text { mengarah pada kiblat. Belum } \\
\text { sesuai dengan penataan } \\
\text { interior ruang kamar seperti } \\
\text { perletakan ranjang untuk tidur }\end{array}$ \\
\hline $\begin{array}{c}\text { Orientasi } \\
\text { bangunan }\end{array}$ & $\begin{array}{l}\text { Menghadap Barat-Timur untuk } \\
\text { bagian depan, tidak terpe- } \\
\text { ngaruh terhadap posisi Ka'bah, } \\
\text { tapi lebih cenderung berorien- } \\
\text { tasi matahari. }\end{array}$ \\
\hline Lingkungan & $\begin{array}{l}\text { Terdapat lahan hijau untuk } \\
\text { peresapan air hujan dan untuk } \\
\text { berolah raga. Green arsitektur } \\
\text { sudah diterapkan }\end{array}$ \\
\hline
\end{tabular}

Tabel diatas menunjukkan adanya : 1). Hijab pada bangunan putri, 2).Zoning, 3). Seni Hias Islami, 4). Layout interior Peruangan, 5). Orientasi bangunan dan fasade bangunan Islami pesma putrid, dan 6). Lingkungan pesma putri

Pintu Masuk Pondok Pesantren Putri KH Mas Mansur.

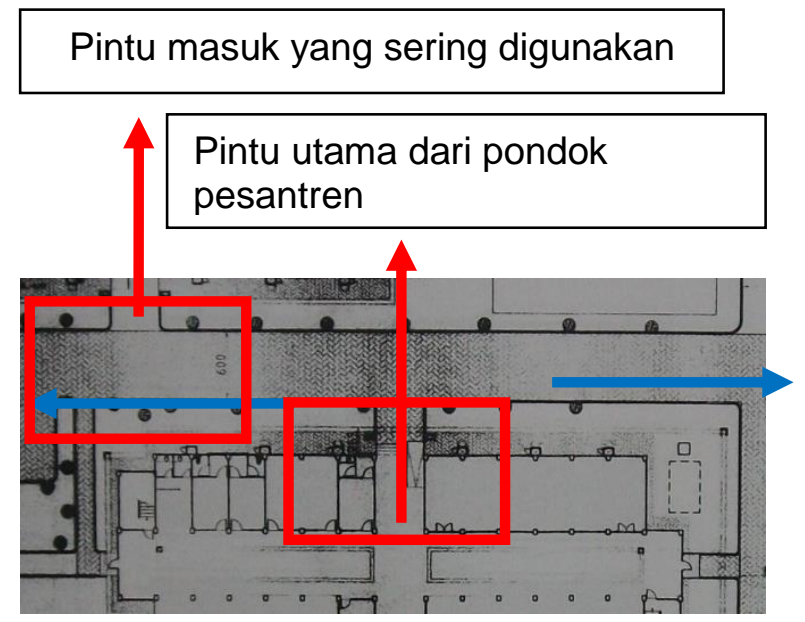

Gambar 3. Denah Pintu Masuk Pesma Putri (Sumber : Survey, 2012)

1. Hijab: Hijab yang berarti pembatas, pemisah ruang umum dengan privat.Pada pemisahan asrama putra dan putri. Pada kantin ada pemisah dari papan kayu untuk membedakan wilayah putra dan putri.

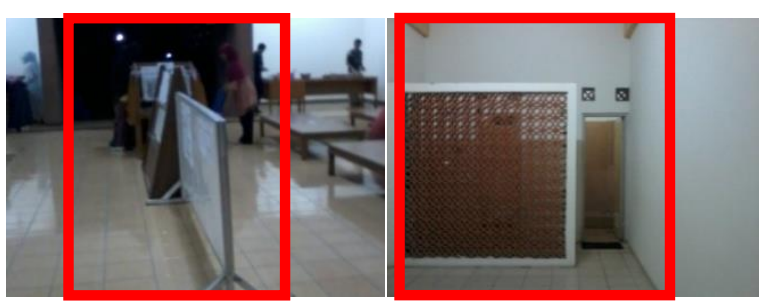

Gambar 4. Hijab partisi kayu pd kantin dan Hijab pada Kamar Mandi

(Sumber: Survey, 2012)

Pada kamar mandi pondok pesantren ini terdapat partisi yang berfungsi sebagai hijab namun letak kamar mandi antara wanita dan pria ini bersebelahan sehingga dikhawatirkan terjadi papasan atau bertemu antara maha-siswa pria dan wanita tersebut ketika sedang di kamar mandi.

Akses masuk pada pondok pesantren $\mathrm{KH}$ Mas Mansur mudah dan dapat dijangkau oleh mobil maupun motor yang datang. Hasil pengamatan menunjukkan data sebagai berikut:

a. Masih bercampur antara mahasiswa yang mengadakan studi keislaman di lantai bawah dengan mahasiswa putri yang tinggal di pondok tersebut.

b. Ornamen yang ada di pondok pesantren $\mathrm{KH}$ Mas Mansur sudah termasuk kriteria ornamen islami, yaitu tidak menampilkan ornamen makhluk bernyawa.

c. Pintu masuk ke area pondok pesantren hanya satu sehingga antara wanita dan pria tidak ada pemisah yang jelas.

Konsep hijab pada tata ruang dalam pada pondok pesantren tersebut belum ada dikarenakan masih bercampurnya antara mahasiswa laki-laki dan putri pada pintu masuk sisi sebelah Timur yang sering digunakan sebagai akses keluar-masuk.

Pada sirkulasi di bagian dalam pun masih terlihat jelas bagaimana antara mahasiswa laki-laki masih dapat berpapasan dengan mahasiswa putri yang tinggal di pondok pesantren tersebut, hal ini terjadi karena tempat belajar dan mengajar pondok baik laki-laki dan perempuan berada di lantai dasar tempat tinggal bagi mahasiswa putri UMS. Pondok pesantren yang ada biasanya ada pemisah 
antara pintu masuk untuk laki-laki dan putri serta proses di dalam belajar mengajar pun juga terpisah, sehingga dapat menghindarkan diri dari fitnah. Selain itu untuk ruang pengelola dan ruang pengajar di pondok pesantren $\mathrm{KH}$ Mas Mansur ini bercampur juga antara pengajar laki-laki dan perempuan. Untuk pondok pesantren yang sudah ada sekarang ini antara pengajar laki-laki serta perempuan ruang pengajarnya dipisah, dengan tujuan untuk menghindarkan diri dari fitnah.

2. Zoning: Pendaerahan pada bangunan Pesma dibagi menjadi daerah umum dan daerah privat. Daerah Umum adalah daerah untuk belajar, mengajar, beribadah bersama, parkir.

3. Seni Hias Islami: terdapat pada: a) fasad bangunan, b) ornamen plafond kantin, c) teralis jendela dan teralis pintu. Ornamen seni hias yang digunakan adalah ornamen yang berorientasi keislaman. Selain untuk menunjukkan dari segi estetika teralis yang digunakan ini berfungsi sebagai keamanan. Jadi ornamen arsitektur Islam di Pesma sudah sesuai dengan kaidah-kaidah geometri arsitektur islam.

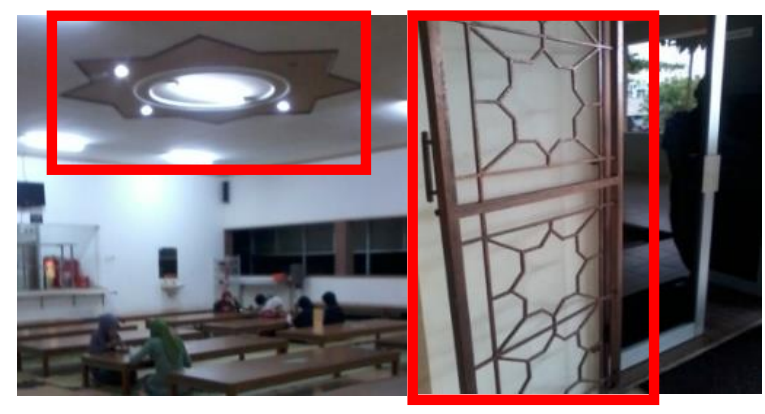

Gambar 5. Ornamen Pada Pondok Pesantren. (Sumber: Survey, 2012)

4. Fasilitas Pesantren: Fasilitas yang dimiliki Pesma adalah: masjid, laboratorium komputer, perpustakaan, ruang kuliah tambahan, ruang tamu, laundry, parkir dan sarana olah raga futsal, seperti terlihat pada Gambar 6.

Pada masjid di area pondok pesantren $\mathrm{KH}$ Mas Mansur terdapat tempat wudhu yang terpisah namun tidak jelas apakah untuk wudhu bagi mahasiswa pondok laki-laki maupun putri. Tidak terdapat juga hijab penutup bagi kaum mahasiswa putri yang hendak shalat dan berwudhu di masjid ini. Dikhawatirkan apabila sedang berwudhu dapat terlihat aurat mahasiswa putri tersebut. Pada interior masjid di area pondok pesantren $\mathrm{KH}$ Mas Mansur ini sangat terbuka. Namun masih belum jelas hijab atau pembatas bagi laki-laki maupun putri yang ingin melaksanakan sholat. Serta kondisi dari masjid tersebut yang kurang terawat.

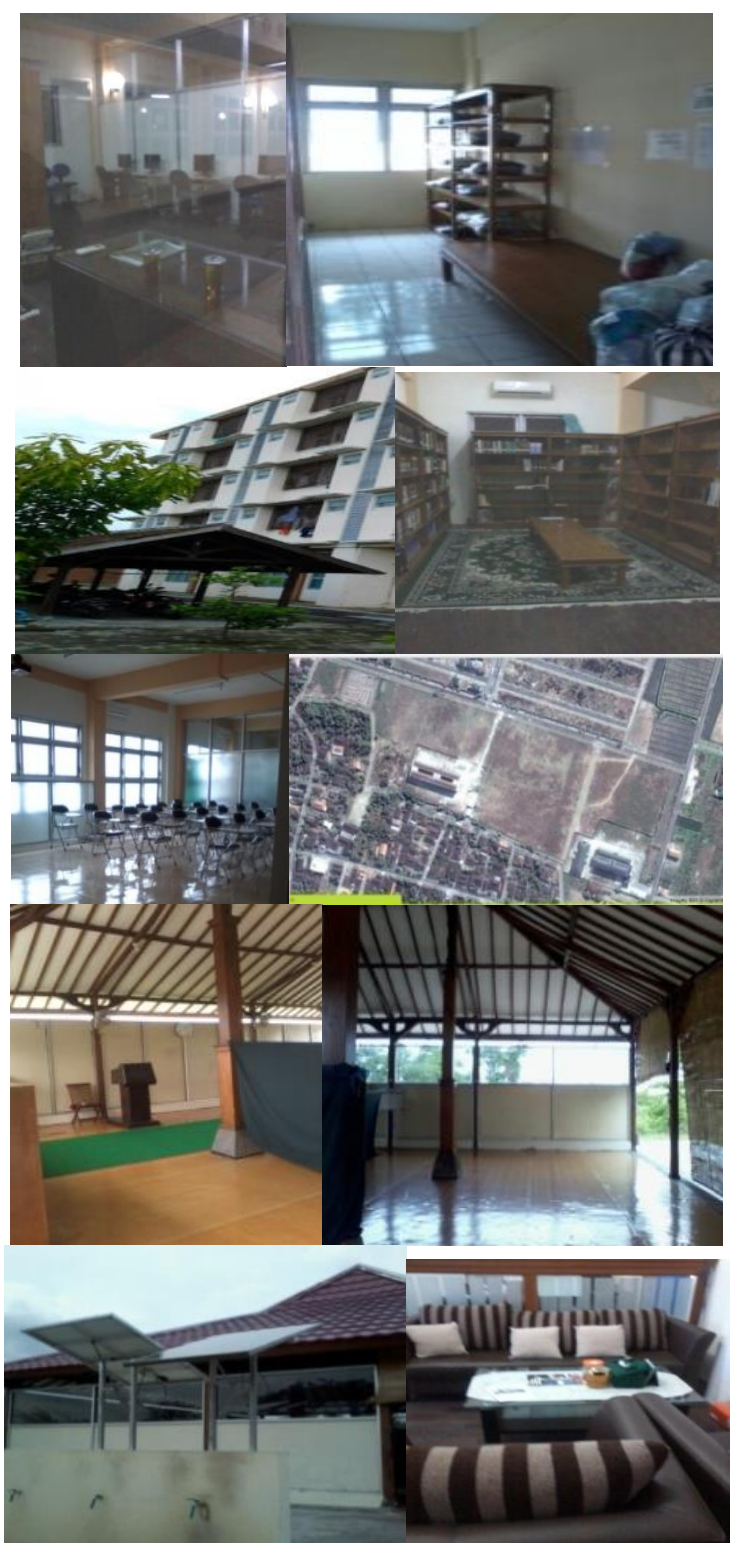

Gambar 6. Fasilitas Pesma (Sumber: Survey, 2012)

5. Sistem Keamanan: pada Pondok Pesantren $\mathrm{KH}$ Mas Mansur sudah terpasang CCTV yang mampu memonitor pengunjung yang datang. Serta mampu memonitor 
mahasiswa pondok pesantren $\mathrm{KH}$ Mas Mansur apabila pulang terlalu larut malam atau ada teman bukan muhrim yang berkunjung di pondok pesantren tersebut.

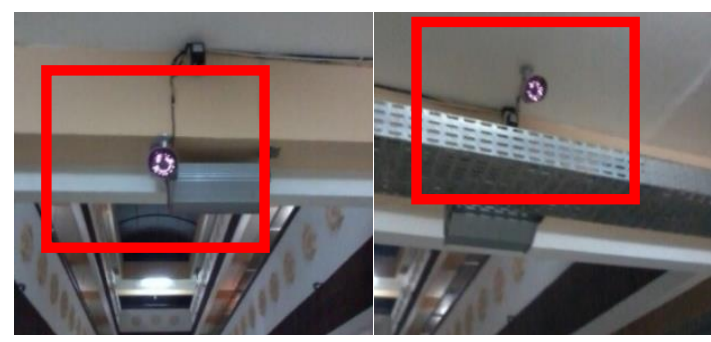

Gambar 7.CCTV Pesantren Mahasiswa (Sumber: Survey, 2012)

\section{Kamar Tidur Unit Hunian}

Terdapat 2 kamar tidur untuk dua mahasiswa santri dan juga terdapat 2 kamar mandi untuk mahasiswa santri tersebut. Kamar mandi (WC), toilet menghadap ke sisi Utara-Selatan, hal itu sesuai dengan arsitektur Islam karena kamar mandi (WC), toilet tidak boleh berada di sisi sebelah barat/kiblat, terlihat pada gambar 8.

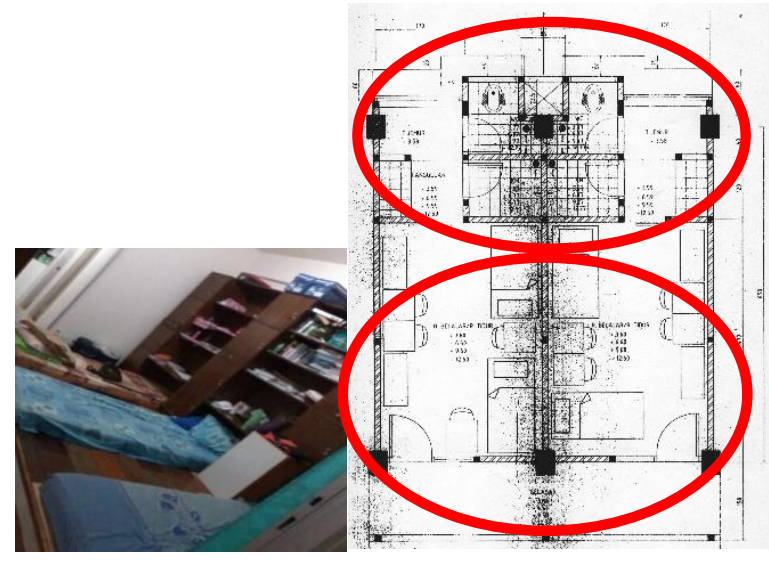

Gambar 8. Kamar Tidur Unit Hunian (Sumber: Survey, 2012)

Kamar tidur sebaiknya lay out furniturenya mencontoh sunnah Nabi pada saat tidur, yaitu menghadap sisi sebelah barat/kiblat dengan kepala dan kaki berada di sisi sebelah Utara-Selatan (pada posisi Indonesia), namun pada pondok pesantren mahasiswa di KH Mas Mansur ini tata letak dari kamar tidur tersebut dirubah sendiri oleh mahasiswa santri tersebut sesuai dengan yang diinginkan.
Tidak terdapat tempat shalat khusus pada hunian bagi mahasiswa santri sehingga apabila ingin menunaikan shalat sendiri di kamar menjadi kurang nyaman khususnya bagi mahasiswi santri putri.

\section{KESIMPULAN DAN REKOMENDASI Kesimpulan}

Hasil penelitian menunjukkan bahwa karakteristik bangunan Islami pada Pesma putri $\mathrm{KH}$ Mas Mansur sebagian besar sudah ada dan dapat disimpulkan sebagai berikut :

a. Bangunan pesma putri $\mathrm{KH}$ Mas Mansur UMS tidak saja sekedar sebagai bangunan fisik yang fungsional untuk tempat tinggal mahasiswa saja. tetapi kenyataanya bangunan ini memiliki dimensi kehidupan Islami dan dapat menjadi alat yang memberi pengaruh bagi suasana hidup yang tidak saja berorientasi pada spasialisasi fungsional tetapi juga temporalisasi ruang yang memberi arah dan pembinaan bagi keberlangsungan hidup dalam komunitas pesantren.

b. Karakteristik bangunan islami terlihat dari adanya zonasi dan tata ruang Islami berdasarkan aturan muhrim, ornamen seni hias Islami (tanpa syirik dan tanpa hiasan makhluk bernyawa), lay out interior peruangan dan orientasi bangunan berdasar kiblat sentris dan fasad bangunan sederhana fungsional.

c. Nilai keislaman secara konkrit dapat ditemukan pada fisik bangunan yaitu pada eksterior dan interior bangunan. Pada eksterior bangunan, terwujud pada perlindungan keamanan dan privasi mahasiswa dengan batasan hijab. Pada Interior, penataan fisik ruang terwujud pada sistem zonifikasi, heriarki ruang, kiblat sebagai orientasi kegiatan yang berdampak pada lay out furniture, perwujudan hijab fisik dan hijab perilaku, hiasan interior/ benda pengingat Allah dan kebersihan ruang yang mengedepankan aturan Islam, kenyamanan berkehidupan dan ruang multifungsi. Benda-benda fungsional dan nilai estetis yang ada dalam bangunan Pesma mempunyai fungsi untuk mendekatkan diri kepada Allah.

d. Penerapan prinsip muhrim terlihat pada adanya hijab. Hijab pada dasarnya adalah sebuah pemisah yang berupa penutup fisik permanen/non permanen (dinding, teras 
depan) agar tidak terganggu privasinya oleh lawan jenis bukan muhrim. Hijab fisik (eksterior) fasad bangunan terdapat pada bangunan, yaitu pada dinding pada realing tiap lantai dan ornamen pada tralis pengaman tiap pintu dilantai bawah, sedangkan hijab perilaku berfungsi ketika ada keterbatasan ruang, sebagai contoh ketika tamu yang datang tidak ada ruang khusus untuk menyambut tamu, tetapi apabila yang bukan muhrimnya maka hanya dapat berbicara di luar pesma (di lantai bawah yang hanya menyediakan kursi panjang saja atau di teras depan. Kamar mandi untuk umum berada di lantai bawah tanpa hijab pemisah, meskipun ada penutup didepan kamar mandi.

e. Telah terdapat seni hias Islami sebagai bagian estetis ruang, fasad bangunan yang tidak mengandung unsur sirik.

\section{Rekomendasi}

a. Bagi Pemerintah :diharapkan pemerintah bisa mengembangkan fasilitas agama dan pendidikan umum yang relevan, perlu memperbanyak pesma serupa sehingga dapat menjalankan aktifitas yang sesuai kaidah keislaman.

b. Bagi Masyarakat: dapat mengubah pandangan masyarakat tentang adanya pesma yang mengedepankan keilmuan dan keislaman yang juga terwujud dalam penataan tata ruang bangunan.

c. Bagi akademisi: dapat dijadikan bahan rujukan untuk penelitian yang tentang hal yang sejenis.

\section{DAFTAR PUSTAKA}

Depag RI, 2006, Qur’an Tajwid dan Terjemahnya, Maghfirah Pustaka, Jakarta

Noe'man, Ahmad.2003. Aplikasi bangunan Islam dalam konsep Islam serta contoh karya nyata,Prosiding seminar arsitektur islam dan tropis, Prodi Teknik Arsitektur Fakultas Teknik UMS, Surakarta

Nurjayanti,W, Wiendu Nuryanti, Arya Ronald, Arif Kusumawanto, 2012, Penggalian Nilai-nilai Kelslaman pada Rumah Tinggal di Kampung Kauman Solo, Prosiding Semnas Arsitektur Islam 2,ISSN: 2252-8962, edisi 24 Mei 2012, Prodi Teknik Arsitektur FT UMS, Surakarta

Nurjayanti,W, Arya Ronald, 2011, Rekayasa Model Disain Rumah Islami berdasar studi eksplorasi di Permukiman sekitar Masjid Menara Kudus, Prosiding Simposium Nasional RAPI X, ISSN:1412.9612, Edisi 13-desember 2011, Fakultas Teknik UMS, Surakarta

Nurjayanti,W, 2004, Aplikasi Konsep Islam pada Rumah Tinggal, Prosiding Simposium Nasional Arsitektur Islam, Arsitektur UMS,Surakarta

Prasodjo Sudjoko dkk, 1975, Profil Pesantren, Jakarta LP3ES

Rasdi, Mohd, Mohd Tajuddin, 2003, Traditional Moslem Architecture in Malaysia, Monograph Kalam Volume 2, Fakulti Alam Bina, University Teknologi Malaysia

Lembaga Study Islam Universitas Muhammadiyah Surakarta, 1994. Study Islam 1,

Sumalyo, Yulianto,2000,Arsitektur Masjid, Gadjah Mada University Press, Yogyakarta

Utaberta, Nangkula, 2007, Rekonstruksi Pemikiran, Filosofi Dan Perancangan Arsitektur Islam Berbasiskan Al-Qur'an Dan Sunnah, Universiti Teknologi Malaysia

http://id.wikipedia.org/wiki/Universitas_Muhammadiyah_Surakarta

Ikrima Iffah Shochfah., Widyastuti Nurjayanti., Identifikasi karakter bangunan Islami pada pesma putri $\mathrm{KH}$ Mas Mansur UMS 
http://pmb.ums.ac.id/2012/FaktaUMS

http://pabelan-online.com/berita/2010/10/menteri-pu-resmikan-pst-dan-pesantren-mahasiswa-ums http://www.muhammadiyah.or.id/id/ ews-1452-detail-pesma-kh-mas-mansur-ikuti-pemeringkatanrusun-tahun-2012. html 